\title{
Effect of Substrate Bias Voltage on the Growth of Chromium Nitride Films
}

\author{
Ho Sang Jang, Yu Sung Kim, Jin Hee Lee, Huigon Chun, Yong Zoo You and Daeil Kim ${ }^{\dagger}$ \\ School of Materials Science and Engineering, University of Ulsan, San 29, Nam-Gu, Ulsan, 680-749, Korea
}

(Received September 3, 2007 : Accepted November 8, 2007)

\begin{abstract}
Chromium nitride (CrN) films were deposited on silicon substrate by RF magnetron sputtering assisted by inductive coupled nitrogen plasma without intentional substrate heating. Films were deposited with different levels of bombarding energy by nitrogen ions $\left(\mathrm{N}^{+}\right)$to investigate the influence of substrate bias voltage $\left(\mathrm{V}_{\mathrm{b}}\right)$ on the growth of $\mathrm{CrN}$ thin films. XRD spectra showed that the crystallographic structure of CrN films was strongly affected by substrate bias voltage. Scanning electron microscopy (SEM) and atomic force microscopy $(A F M)$ results showed that surface roughness and grain size of the $\mathrm{CrN}$ films varied significantly with bias voltage. For $-80 \mathrm{~V}_{\mathrm{b}}$ depositions, the $\mathrm{CrN}$ films showed bigger grain sizes than those of other bias voltage conditions. The lowest surface roughness of $0.15 \mathrm{~nm}$ was obtained from the $\mathrm{CrN}$ films deposited at $-130 \mathrm{~V}_{\mathrm{b}}$.
\end{abstract}

Key words Chromium nitride; Inductive coupled plasma (ICP); Substrate bias; AFM; XRD.

\section{Introduction}

Transition metal nitrides such as chromium nitride $(\mathrm{CrN})$ have been proposed as promising hard coating thin films due to their high hardness, wear, corrosion and high temperature oxidation resistance. ${ }^{1-3)}$

Currently, ion beam system, ${ }^{2)}$ cathodic arc, ${ }^{4)}$ and magnetron sputtering ${ }^{5)}$ methods have been developed to obtain high rate deposition processes of chromium nitride $(\mathrm{CrN})$ thin films for cost effective industrial applications. Among these deposition technologies, magnetron sputtering is recommended as an efficient method for the synthesis of high rate deposited $\mathrm{CrN}$ films. It has also been reported that the main parameters controlling the properties of $\mathrm{CrN}$ films in a magnetron sputtering process are substrate temperature and nitrogen gas partial pressure in a sputtering atmosphere. ${ }^{6)}$

In this study, $\mathrm{CrN}$ films were prepared with a magnetron sputtering system assisted by inductive coupled plasma (ICP). The effect of negative substrate bias voltage $\left(\mathrm{V}_{\mathrm{b}}\right)$ on the surface morphology and microstructure of the films was investigated. Microstructures were analyzed by $\mathrm{X}$-ray diffraction (XRD), and surface morphology properties were evaluated by scanning electron microscopy (SEM) and atomic force microscopy (AFM).

${ }^{\dagger}$ Corresponding author

E-Mail : dkim84@ulsan.ac.kr (D. I. Kim)

\section{Experimental procedures}

CrN films were deposited on single crystal Si (100) wafers by an RF magnetron sputter assisted by inductive coupled nitrogen plasma. Fig. 1 shows the schematic diagram of the system used in this study. The antenna conductor, which was made of a $\mathrm{Cu}$ tube for water cooling, was located on the side wall of the chamber approximately $100 \mathrm{~mm}$ from the substrate. To produce $\mathrm{N}^{+}$ ions, a three turn antenna with a diameter of $200 \mathrm{~mm}$ was coupled to a radio frequency (RF) power generator at $13.56 \mathrm{MHz}$ via a matching network. The cylindrical quartz chamber for the $\mathrm{N}^{+}$ion source was $180 \mathrm{~mm}$ in diameter and $250 \mathrm{~mm}$ in length. The RF power for the antenna conductor was kept constant at $100 \mathrm{~W}$. The ionic current density was equal to $6 \mu \mathrm{A} / \mathrm{cm}^{2}$.

Pure argon (Ar, 99.99\%) and nitrogen $\left(\mathrm{N}_{2}, 99.99 \%\right)$ gas were introduced after the pressure in the chamber was lowered to $1 \times 10^{-5} \mathrm{~Pa}$. The Ar partial pressure was kept constant at $0.3 \mathrm{~Pa}$, while $\mathrm{N}_{2}$ partial pressure was kept constant at $0.05 \mathrm{~Pa}$. $\mathrm{CrN}$ films were deposited from a pure $\mathrm{Cr}$ target $(99.99 \%)$ by an RF magnetron sputter in an $\mathrm{Ar}$ and $\mathrm{N}_{2}$ atmosphere.

During the deposition process, substrate temperature was evaluated with a thermal couple located on the back of the holder plate. Although deposition was carried out without intentional substrate heating, substrate temperature increased up to 200 due to the generation of plasma in the chamber. 


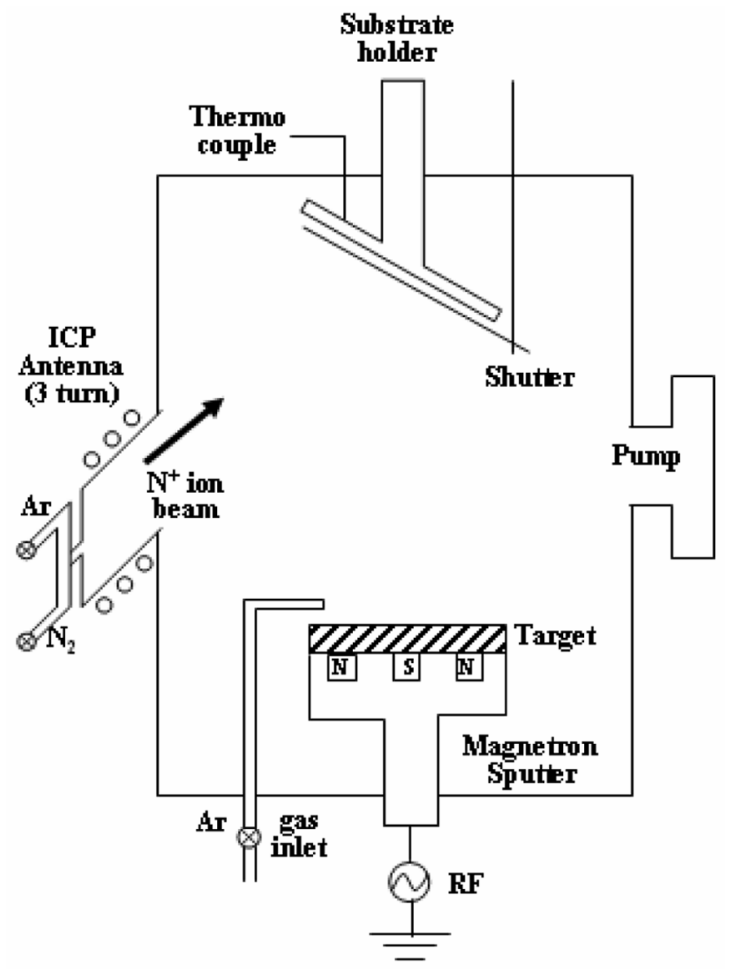

Fig. 1. Schematic illustration of the ICP-assisted RF magnetron sputtering system.

Cr target power and distance from target to substrate were kept constant at $100 \mathrm{~W}$ (power density: $2.5 \mathrm{~W} / \mathrm{cm}^{2}$ ) and $100 \mathrm{~mm}$, respectively. Negative substrate bias voltages $\left(-30 \mathrm{~V}_{\mathrm{b}},-50 \mathrm{~V}_{\mathrm{b}},-80 \mathrm{~V}_{\mathrm{b}},-100 \mathrm{~V}_{\mathrm{b}},-130 \mathrm{~V}_{\mathrm{b}}\right)$ were applied to the substrate by a DC power supply. Prior to deposition, $10 \mathrm{~min}$ of re-sputtering with a sputtering power of $150 \mathrm{~W}$ was performed to remove the metal-nitride layer of the target surface due to previous depositions.

Chemical compositions of these films were determined by quantitative energy dispersive X-ray (EDS) analysis using an EDAX DX-4 analyzer. Crystallographic structure was characterized by X-ray diffraction (XRD) using $\mathrm{Cu} \mathrm{K} \alpha$ radiation. Surface morphology and rms roughness were measured by scanning electron microscopy (SEM) and atomic force microscopy (AFM), respectively. Thickness was measured using an AlphaStep 500 profiler.

\section{Results and discussion}

Fig. 2 shows the deposition rate at different substrate $\mathrm{V}_{\mathrm{b}}$. Deposition rates decreased from $15.4 \mathrm{~nm} / \mathrm{min}$ to 10 $\mathrm{nm} / \mathrm{min}$. When the deposition process was carried out

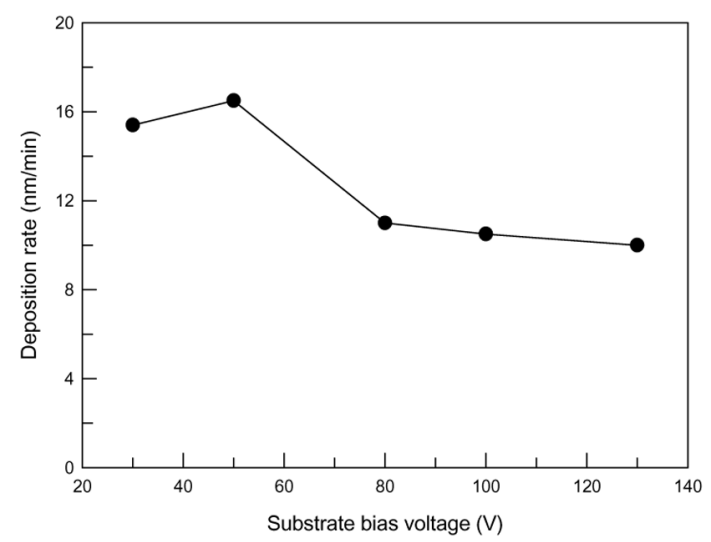

Fig. 2. Deposition rate as a function of substrate bias voltage.

with a negative substrate bias, the $\mathrm{N}^{+}$ions of the plasma were attracted towards the substrate holder, thus transferring their kinetic energy to the surface atoms. As seen in Fig. 2, if the incident ion energy, which increased with increasing negative bias voltage, is high enough, this effect may induce a re-sputtering of the coating, giving rise to lower deposition rates. ${ }^{1)}$

Nitrogen content in a film also depends on the substrate bias voltage. Nitrogen content measured by EDS was about 49 at $\%$ when $\mathrm{V}_{\mathrm{b}}=-30 \mathrm{~V}$ and $47 \mathrm{at} \%$ for $\mathrm{V}_{\mathrm{b}}=-$ $130 \mathrm{~V}$. This suggests that the nitrogen content of the deposited films was reduced by high energy ion bombardments. This result is in agreement with previous

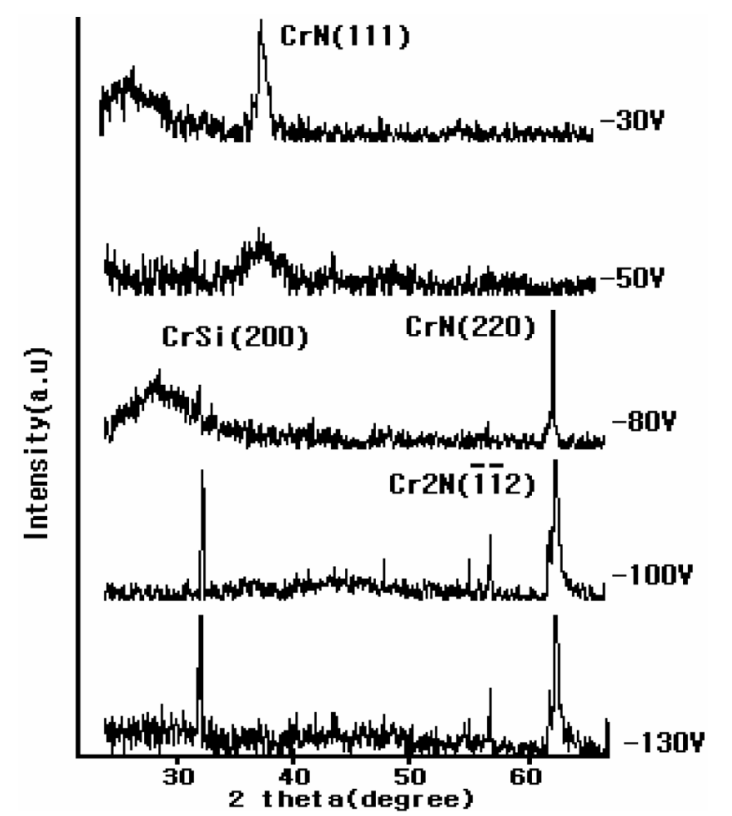

Fig. 3. XRD spectra for $\mathrm{CrN}$ films deposited at various substrate bias voltages. 
reports by T. Hurkmans et al. ${ }^{7)}$ and C. Gautier et al. ${ }^{8)}$

Fig. 3 shows XRD spectra of $\mathrm{CrN}$ films deposited under different substrate bias voltages. Crystallographic structure of the $\mathrm{CrN}$ films was strongly affected by substrate bias voltage. CrN (111) films with FCC structure were grown at $\mathrm{V}_{\mathrm{b}}=-30 \mathrm{~V}$. The XRD spectra showed that the phases of $\mathrm{CrN}$ films changed from $\mathrm{CrN}$ to $\mathrm{Cr}_{2} \mathrm{~N}+\mathrm{CrSi}$ as a function of substrate bias voltage. At $-80 \mathrm{~V}_{\mathrm{b}}$, the $\mathrm{CrN}$ (111) peak disappeared, while a $\mathrm{CrN}$ (220) peak appeared in the XRD spectrum. Film deposited at $-130 \mathrm{~V}_{\mathrm{b}}$ showed considerably more diffraction peaks, as seen in Fig. $3\left(\mathrm{~V}_{\mathrm{b}}=-130 \mathrm{~V}\right)$. This is due to growing films being bombarded by energetic ions, which increases nucleation seeds for grain growth. ${ }^{9)}$

Fig. 4 shows plain view scanning electron micrographs (SEM) for $\mathrm{CrN}$ films deposited at various $\mathrm{V}_{\mathrm{b}}$ conditions. Thickness of the films was kept constant at $100 \mathrm{~nm}$. Microstructure was affected by the applied $V_{b}$. The film
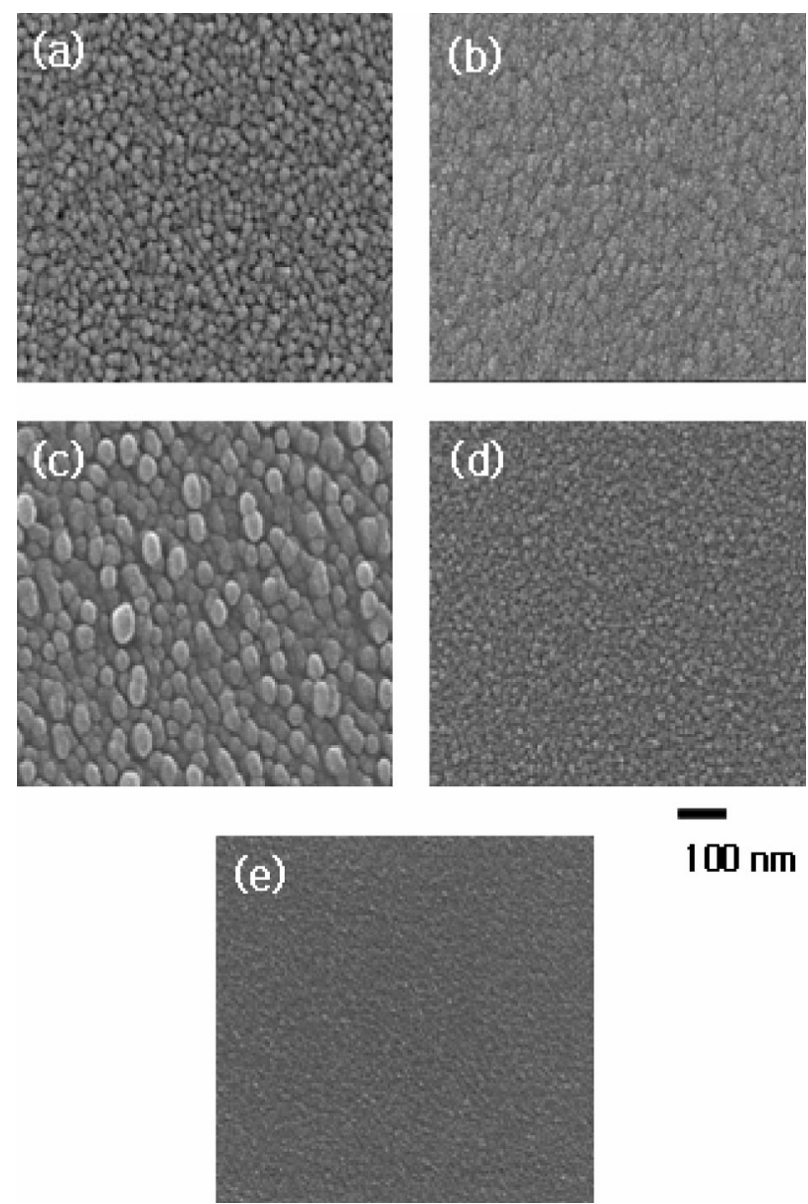

$100 \mathrm{~nm}$

Fig. 4. Plain view scanning electron micrographs (SEM) for CrN films deposited at various substrates bias voltages: (a) $30 \mathrm{~V}$, (b) $-50 \mathrm{~V}$, (c) $-80 \mathrm{~V}$, (d) $-100 \mathrm{~V}$, (e) $-130 \mathrm{~V}$. deposited with $-80 \mathrm{~V}_{\mathrm{b}}$ shows larger grain sizes than those of films deposited at other $\mathrm{V}_{\mathrm{b}}$ conditions. During deposition, $\mathrm{N}^{+}$ions transfer their kinetic energy to the surface adatoms. The transferred energy increased the mobility of the adatoms on the surface, and consequently larger grains were formed. However, the grain size of $\mathrm{CrN}$ films deposited at $-130 \mathrm{~V}_{\mathrm{b}}$ was smaller than that deposited at $80 \mathrm{~V}_{\mathrm{b}}$. It is well known that ion bombardment due to biasing the substrate causes a reduction of the grain size. Ion beam energy that is too intense may increase the concentration of defects and formation of complex defects, thus hindering recrystallization. ${ }^{10)}$

Fig. 5 shows AFM images of $\mathrm{CrN}$ film deposited at a bias voltage of $-50 \mathrm{~V}_{\mathrm{b}}$. The films show the island growth. In this study, surface average roughness $(\mathrm{Ra})$ of

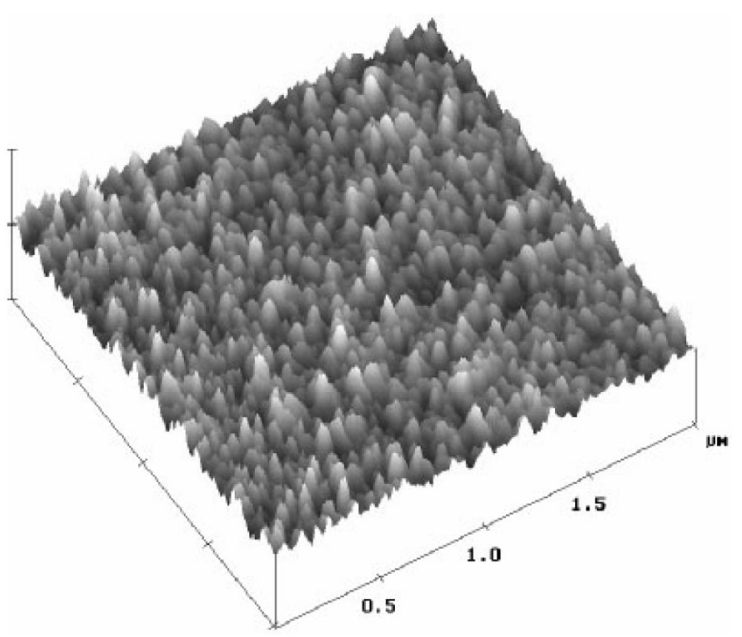

Fig. 5. Atomic force microscopy (AFM) images for $\mathrm{CrN}$ film surfaces deposited at substrate bias voltage of $-50 \mathrm{~V}$.

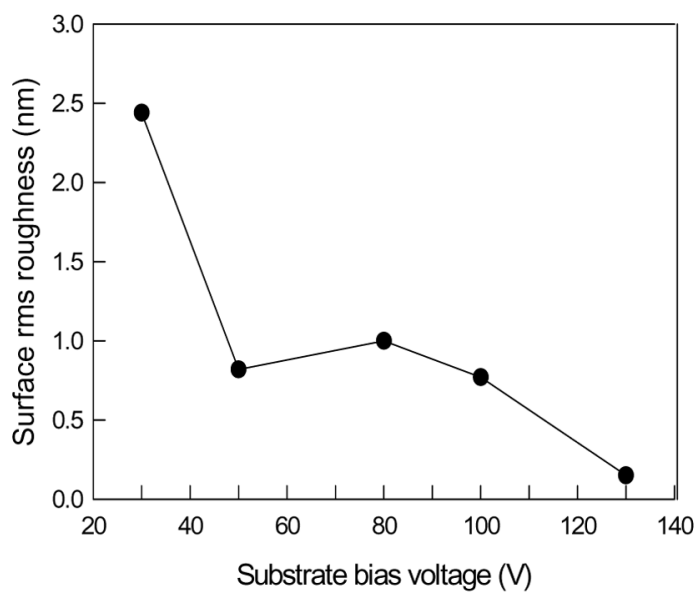

Fig. 6. Surface average roughness (Ra) of the films deposited at various substrate bias voltages. 
the films was decreased with $\mathrm{V}_{\mathrm{b}}$ due to intense ion beam bombardment. The lowest roughness of $0.5 \mathrm{~nm}$ was obtained from $\mathrm{CrN}$ films deposited at a bias voltage of $130 \mathrm{~V}_{\mathrm{b}}$, as seen in rms data graph (Fig. 6).

\section{Conclusion}

An ICP-assisted magnetron sputtering system was used to deposit chromium nitride $(\mathrm{CrN})$ films. To investigate the effect of substrate bias voltage on $\mathrm{CrN}$ film properties, $\mathrm{CrN}$ films were deposited without intentional substrate heating under different substrate bias voltage conditions.

The deposition rate decreased with bias voltage due to intense $\mathrm{N}^{+}$ion bombardment. XRD spectra showed that the crystallographic structure of the $\mathrm{CrN}$ films was strongly affected by the substrate bias voltage. Grain size and surface roughness were also affected by substrate bias voltage.

\section{References}

1. E. Forniés, R. Galindo, O. Sánchez and J. Albella, Surf. Coat. Technol., 200, 6047 (2006).

2. J. Lim and C. Lee, Mat. Chem. Phys., 95, 164 (2006).

3. O. Banakh, P. Schmid, R. Sanjinés and F. Lévy, Surf. Coat. Technol., 163, 57 (2003).

4. K. Chang, S. Chung, S. Lai and H. Shih, Appl. Surf. Sci., 236, 406 (2004).

5. A. Ehiasarian, W. Münz, L. Hultman, U. Helmersson and I. Petrov, Surf. Coat. Technol., 163, 267 (2003).

6. C. Gautier, H. Moussaoui, F. Elstner and J. Machet, Surf. Coat. Technol., 86, 254 (1996).

7. T. Hurkmans, D. Lewis, H. Paritong, J. Brooks and W. Munz, Surf. Coat. Technol., 114, 52 (1999).

8. C. Gautier and J. Machet, Thin Solid Films, 295, 43 (1997).

9. D. Kim, Appl. Surf. Sci., 218, 79 (2003).

10. D. Kim and S. Kim, Surf. Coat. Technol., 154, 204 (2002). 